\title{
LONDRES 2012 AÑO OLÍMPICO INVITA A PREGUNTAR: ¿POR QUÉ UNA CÁTEDRA OLÍMPICA?
}

\section{LONDON 2012 OLIMPIC YEAR INVITES TO ASK: WHY AN OLIMPIC CHAIR?}

\author{
José Antonio García Forero ${ }^{1}$
}

\begin{abstract}
${ }^{1}$ Licenciado en Educación Física, Deportes, Salud y Recreación. Profesional Especializado en Atletismo, Teoría del Entrenamiento. Director Cátedra de Estudios Olímpicos-CEO-Universidad de Ciencias Aplicadas y Ambientales U.D.C.A, Fac. Ciencias del Deporte. Calle 222 No. No. 54-37, Bogotá D.C. E- mail: jogarfor@gmail.com.
\end{abstract}

Rev. U.D.C.A Act. E Div. Cient. 15 (Supl. Olimpismo): 5 - 11, 2012

\section{RESUMEN}

La realización de los Juegos Olímpicos (J.J.O.O.) de Londres 2012 invita a estudiar la historia del olimpismo, a lo que se dedica, someramente, este artículo. En la antigüedad, como en la época moderna, los juegos se celebran cada cuatro años. En la época antigua, se prohibían las guerras para celebrar los juegos, mientras que en la actualidad, se suspendieron los juegos para perpetrar las guerras. Para mantener vivo el espíritu olímpico, el Comité Olímpico Internacional (COI) creó la Academia Olímpica Internacional (AOI) y ésta, a las Academias Olímpicas Nacionales (AON) que, a su vez, crearon las Cátedras de Estudios Olímpicos (CEO), que abarcan en detalle los acontecimientos olímpicos y se detienen en la definición clásica de los J.J.O.O., que corresponde a una convocatoria para competir en deportes aprobados, a nivel internacional. La Universidad de Ciencias Aplicadas y Ambientales U.D.C.A, como líder de las CEO en Colombia, orienta y profundiza en el olimpismo con la filosofía de sus creadores.

Palabras clave: Olimpismo, deportes aprobados, Pierre de Coubertain, cátedra olímpica.

\section{SUMMARY}

The carrying out of the Olympic Games London 2012 invites to study the history of the Olympics, to which this article is, basically, dedicated. In the olden as well in the modern days Olympic Games are celebrated every four years. In the ancient times wars were prohibited while celebrating the games. In the modern times the games were suspended to be at war. To maintain the Olympic Spirit the COI (International Olympic Committee) created the AOI (International Olympic Academy) and this one the I.O.A. (The International Olympic Academy) which, at the same time created the CEO (The Olympic Studies Professorship); the last ones include, with details the Olympic happenings and maintain the classic definition of the games which corresponds to the summon to compete within internationally approved sports. The University of Applied and Environmental Sciences U.D.C.A, as leader of the CEO in Colombia, guides and deepens into the Olympics with the philosophy of its creators.

Key words: Olympics, approved sports, Pierre de Coubertain, Olympic Studies Professorship.

\section{INTRODUCCIÓN}

El Comité Olímpico Español (COE), en su página web AO Internacional (s.f.) registra el deseo del Barón Pierre de Coubertain, quien manifestó: "Creo que la apertura, con carácter permanente, de un centro de estudios dedicado al Olimpismo, sería más productivo que cualquier otra iniciativa, para lograr mantener mi trabajo, ayudarlo a progresar y protegerlo de influencias peligrosas".

En la misma página, se detalla que un año después de su muerte, Carl Diem (1966), a quien se le conoce como escritor de historia de los deportes y Ioannis, quien se desempeñaba como presidente del Comité Olímpico de Grecia (1938), inició el proceso para hacer realidad el deseo de Coubertain, presentando la propuesta al Comité Olímpico Internacional (COI), que solo hasta 1961 y después de muchos estudios, inauguró la Academia Olímpica Internacional 
(I.O.A., 2012), con un objetivo específico: "La creación de un centro intelectual, donde una élite de la juventud universitaria de todo el mundo, se reúna y sea educada en los ideales Olímpicos, bajo la dirección de reconocidas autoridades y expertos en la materia".

Dentro de las gestiones del nuevo ente, I.O.A., está el difundir por el mundo el olimpismo, para lo cual, por intermedio del COI, ordena a todos los Comités Olímpicos Nacionales acreditados crear la Academia Olímpica Nacional, en sus respectivos países (Quiroga, 2000).

Creada la Academia Olímpica Colombiana, en 1992, establece dentro de sus programas las llamadas "Tertulias Olímpicas", que se llevan a cabo cada mes, a las cuales, asisten los estudiantes de la Facultad de Ciencias del Deporte de la U.D.C.A., quienes solicitaron descentralizar los estudios olímpicos para responder al sueño del Barón de Coubertain, al objetivo de la creación de la AOI. Esta aspiración fue concretada por la AOC, una vez comprobados los requisitos: reconocimiento oficial de la Universidad; aprobación de los estudios; acreditación de la facultad de Ciencias del Deporte; visión y misión, entre otros muchos. A la U.D.C.A, le fue otorgada la responsabilidad de ser la primera Universidad en Colombia en institucionalizar la CÁTEDRA OLÍMPICA, con la denominación de "ESTUDIOS OLIMPICOS Y DEL DEPORTE" (nombre original, posteriormente denominada CEO, Centro de Estudios Olímpicos).

Con esta responsabilidad fue inaugurada la Cátedra, el 28 de octubre de 2009, en acto especial, con la asistencia de las directivas de la Universidad, del COC, de la AOC, de representantes de varias universidades de Bogotá y del estudiantado, directivas, docentes de Ciencias del Deporte y otras facultades.

\section{CÁTEDRA OLÍMPICA}

En reunión del COC, la AOC y la U.D.C.A, con su facultad de Ciencias del Deporte, se establecieron los contenidos de la cátedra, en seis extensos nodos, tratando de abarcar el profundo universo del Olimpismo, con un objetivo especial: "Abordar en el seno de la Universidad, a través de la cátedra de estudios olímpicos y del deporte, aspectos relevantes y pertinentes a la academia, con el fin de divulgar los valores y los principios del deporte, contribuyendo así, a la formación integral de los estudiantes de la facultad, en especial, los entes universitarios y todos los entornos, mediante el análisis de problemáticas de los deportes".

La temática propuesta abarca títulos de inmenso contenido, como son: Cultura Helénica; Juegos Panhelénicos; Juegos de la antigüedad; Pierre de Frédy, Baron de Coubertain;
Restauración de los Juegos Olímpicos; Juan Antonio Samaranch; Amenazas contra el Olimpismo; Mujer y deporte; Jaques Rougge; Juegos Olímpicos de la Juventud; Justificación del deporte; Deporte y desarrollo social; Sistema Nacional del Deporte en Colombia; Comité Olímpico Colombiano; Relación del deporte con el sector público y privado, cada uno con extensos ítems.

Así mismo, se estableció un propósito: "Coadyuvar en el estamento Universitario y Deportivo en la formación de una cultura de Paz, a través del Olimpismo y el estudio de los deportes y la actividad física, como un medio privilegiado para cultivar valores: La convivencia pacífica, la vigencia del orden justo, el respeto por la dignidad humana, el respeto y cuidado del medio ambiente, el análisis y divulgación de los valores y principios del deporte desde todos los puntos de vista, contribuir a la formación integral de los ciudadanos colombianos y extranjeros que asistan a la U.D.C.A, teniendo como parámetros PENSAR, IMAGINAR, CREAR, INTERPRETAR, CONCEPTUALIZAR Y PROPONER, en sesiones donde prima el debate".

Con motivo del año olímpico, se ha profundizado el estudio y el análisis de acontecimientos de la actividad física, hasta encontrar momentos de competitividad organizada. Salgado (2009), apoyado en investigaciones arqueológicas, en observación y en referencias de diferentes fuentes, manifiesta, en su conferencia, la evolución de las comunidades primitivas, elementos, como identidad social, adaptación y cuantificación-mínima, en las antiguas y, máxima, en las actuales.

\section{ALGO DE HISTORIA}

\section{Época antigua}

Naranjo (2010a), de manera folclórica, presenta a un Homo neanderthalensis (Figura 1), designándole el honor de haber sido el primer deportista de la historia. Le da el nombre de Gronk, al hombre que vivió alrededor de 200 a 250 mil años antes que nosotros.

En la conferencia dictada por el profesor Manuel Salgado (2009), en marzo 30 del 2009, en la cátedra de Deporte y Sociedad de la facultad de Ciencias del Deporte de la U.D.C.A, el conferenciante hizo énfasis en que el deporte no solo se debe estudiar en Grecia sino que es necesario encontrar otros orígenes y, para ello, refirió cómo dentro de las competencias deportivas aparece la sociedad primitiva australiana, de hace 25.000 años, donde sus habitantes lanzaban una caña, como jabalina y luchaban por la posesión de una vara, en un juego denominado Mungan-mungan. Además, practicaban juegos con semillas o frutas, golpeadas con estacas y el PRUN que eran batallas entre grupos (García, 2006). 


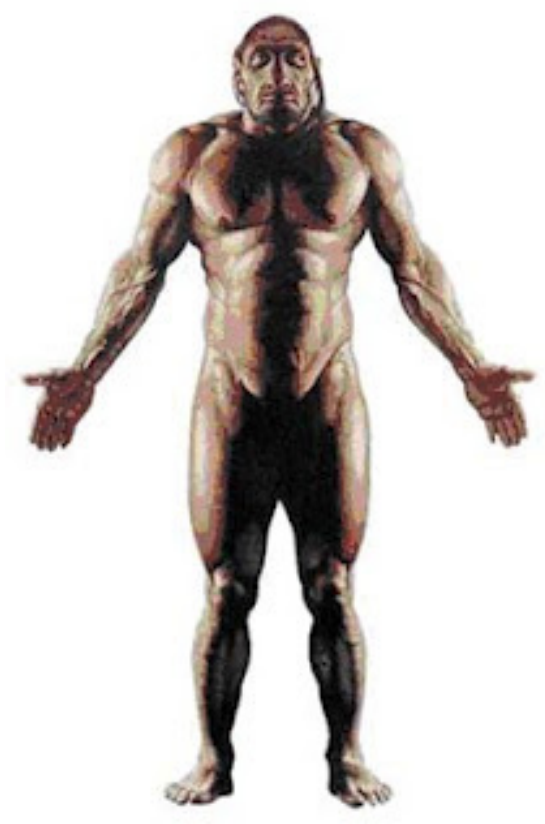

Figura 1. Primer deportista de la historia, llamado GRONK. Tomado de Naranjo (2010a).

De acuerdo con Hernández (2010), mucho más reciente en Mesopotamia, 3.400 años a.C., se registran carreras de carros tirados por caballos, boxeo, natación, carreras y lucha. Así mismo, en Egipto, 3.000 años a.C., por referencias visuales (paredes, tumbas, esculturas), escritos y otros elementos históricos, describen carros (Tutankhamon), arcos (madera), venablos de madera, arpones y anzuelos para la pesca (Figura 2).
Ya en la cuna del olimpismo, se encuentra como referencia la isla de Creta, 1.500 años a.C., donde se registran carreras y saltos, juegos con toros, pugilato, danzas y caza.

Al estudiar la llíada (Homero, 1998), pensamos encontrar las competencias organizadas en el canto 23 con los "Juegos en Honor a Patroclo", pero vemos que el anciano Néstor, quien compitió en las cuadrigas llegando en quinto lugar, fue

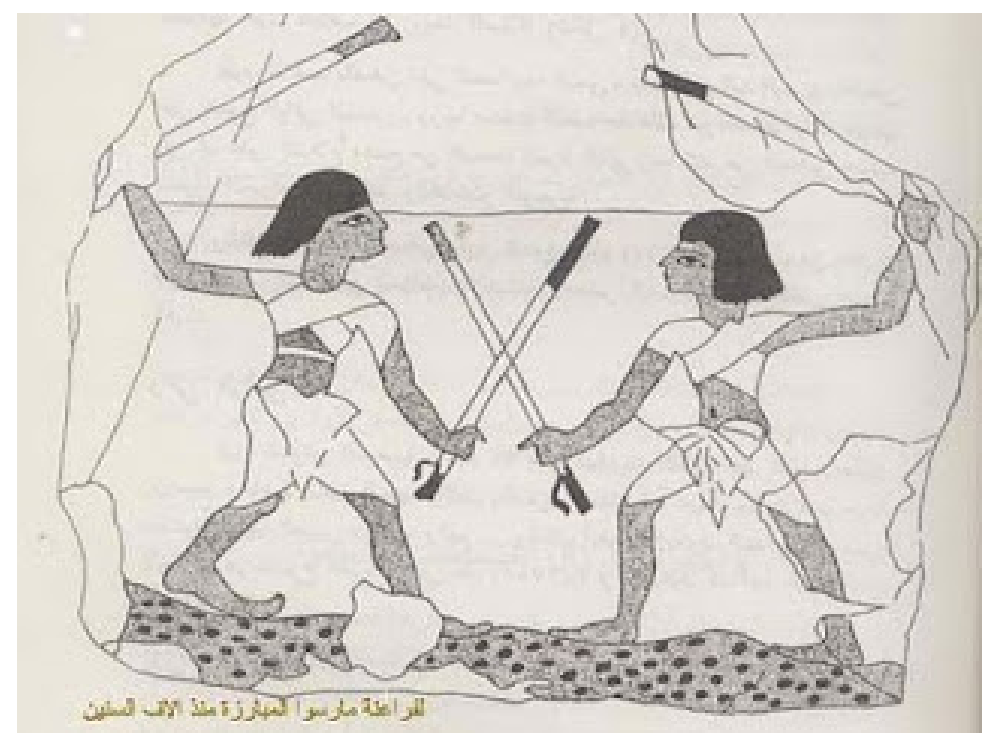

Figura 2. Del deporte antiguo - Orígenes del deporte. Publicado por Valen Naranjo 2010b. Disponible desde Internet en: http://teoriaehistoriadeldeportevalennaranjo.blogspot.com/ (con acceso 10/01/12). 
premiado por Aquiles y el galardonado comentó que "Había participados en anteriores Juegos".

El colombiano Hugo Ángel Jaramillo (1970), en su libro "Los deportes: Orígenes, evolución y etapa olímpica”, registra con lujo de detalles la cronología de los Juegos olímpicos antiguos, desde 776 a.C., hasta los 194 Juegos Olímpicos Antiguos, cuatro años a.C., completando 197 Juegos, nueve años d.C.

La historia nos presenta, como Juegos olímpicos antiguos, los Ístmicos, en honor a Poseidón; los Nemeos, a Hércules; los Píticos, en honor a Apolo y los Panhelénicos, a Zeus" (Durantez, 1975).

En el libro "De Cero al Gesto", de García (2006), encontramos referencia de los orígenes remotos del atletismo. Durantez (2010) registra acontecimientos de la época antigua del olimpismo, en magistral conferencia, dictada en la Academia de la Lengua, con motivo de la quincuagésima tertulia olímpica de la AOC.

No podemos, en el estudio, dejar por fuera a imperios como Roma, su invasión a Grecia y la migración de cultura, incluyendo el deporte. Allí llegó la decadencia y fue precisamente el emperador Romano, Teodosio I, quien puso fin a los Juegos, en 392 d.C.

\section{Época moderna}

El griego Evangelius Zapas quiso revivir los Juegos olímpicos antiguos y convocó, para su primera realización, en noviembre de 1859; tuvo poca asistencia, pero siguió insistiendo, para noviembre de $1870 \mathrm{y}$, posteriormente, para mayo de $1875 \mathrm{y}$, en la misma fecha, en 1889, pero su fracaso fue total; todo su interés y su capital lo donó al Barón de Coubertain, quien para esa fecha ya estructuraba el proyecto de renovación de los juegos, congregando a países que personalmente visitó, para crear en junio de 1894, el COI (2009), que tomó como tarea realizar los Juegos Olímpicos modernos.

Es de anotar que desde esa época hasta la fecha, el COI solo ha tenido ocho presidentes: Demetrius Vikelas, griego, 1894-1896; Barón Pierre de Coubertain, francés, 1896-1925; Henry de Baillet Latour, belga, 1925-1947; Sigfrid Edstrom, sueco, 1947-1952; Avery Brundage, USA, 1952-1972; Lord Killanin, Irlandés, 1973-1980; Juan Antonio Samaranch, español, 1980-2001 y Jaques Rougge, belga, 2001 a la fecha. Todos han realizado excelente gestión, pero en el desarrollo de la cátedra, se destacan tres que merecen mención, por su trascendencia en el desarrollo de los Juegos.

Pierre de Frédy, Barón de Coubertain (Figura 3). Educador, filósofo, humanista y líder, tiene como mérito la creación del COI y la restitución de los juegos olímpicos modernos, exclusivos para aficionados, con la consigna de "...lo importante no es ganar sino participar”; intervenían varones aficionados y no estaba de acuerdo con la participación femenina.

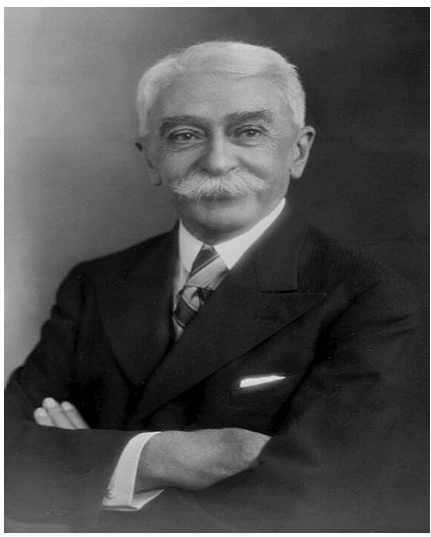

a

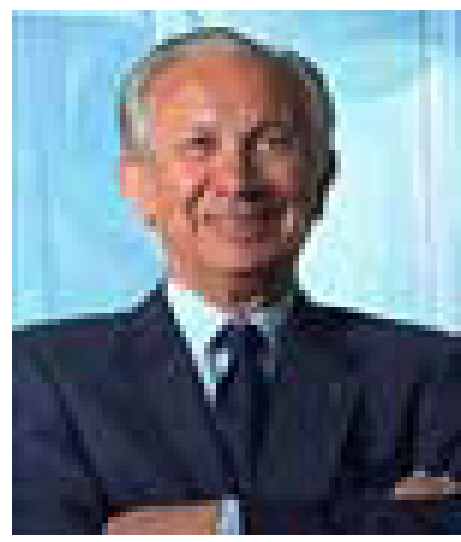

b

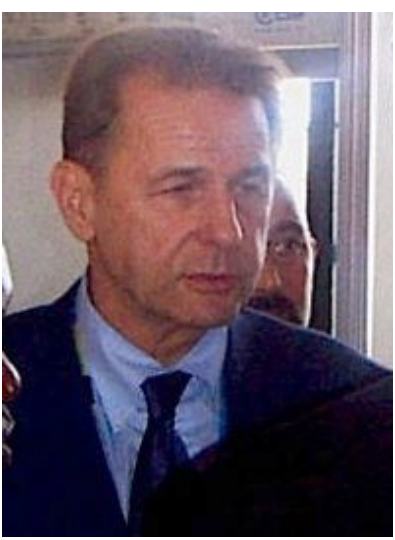

C

Figura 3. Presidentes del Comité Olímpico Internacional: a) Pierre de Frédy, Barón de Coubertain; b) Juan Antonio Samaranch y c) Jaques Rougge. Tomado respectivamente de:

http://www.atletismomdq.com.ar/OLIMPIADAS/renacimiento\%20y\%20misiones.pdf;http://www.rtve.es/mediateca/fotos/20100421/juan-antonio-samaranch-vida-dedicada-olimpismo/50396.shtm; http://es.wikipedia.org/wiki/Jacques_Rogge (con acceso a todos 22/02/2012). 
Juan Antonio Samaranch (Figura 3). Político, dirigente deportivo. Su mérito se debe a la apertura de los juegos a deportistas profesionales, dando término a la filosofía del Barón Pierre de Coubertain. Con la financiación de los juegos olímpicos por los patrocinadores y las ventas, se dota a todos los entes de la estructura olímpica, con cantidades de dinero para capacitación, preparación, desplazamientos y actuación en los eventos deportivos. Esto, ha generado unos macro juegos con grandes inversiones y derroche de lujo en las instalaciones, dotaciones, ceremonias de inauguración y clausura, especialmente, lo que solo pueden realizar las ciudades con grandes capitales.

Jaques Rougge (Figura 3). Dirige actualmente el COI, su gestión es conducida, en especial, a la reserva deportiva; ha creado los juegos olímpicos de la juventud, donde participan jóvenes, damas y varones, entre 14 y 18 años. Los primeros, se celebraron con éxito en Singapur, 2010 y los próximos están programados para 2014, en Nanjin-China. Para el 2018 está por concederse la sede. Medellín, Colombia aspira, con lujo de razones, a ser centro de estos juegos.

\section{JUEGOS OLÍMPICOS DE LONDRES}

Existe infinidad de información sobre estos juegos. En la Cátedra de Estudios Olímpicos, los estudiantes leen, para luego debatir y discutir sobre ello; además, se realizó un foro especial, contando con la presencia de la eminente filóloga griega, Georgia Kalsidou (2010), radicada en Colombia, quien forma parte de la AOC, como miembro activo y colabora con el CEO de la U.D.C.A. Actualmente, se desempeña en el Instituto Caro y Cuervo. La filóloga presentó una magnífica y extensa conferencia sobre Grecia y los juegos de Londres, referenciando, en especial, el logo (Figura 4) y la mascota (Figura 5), con la concepción de un mensaje que no es precisamente el que se considera debe ser enviado a las nuevas generaciones. Expuso un símil gráfico, parangonando la figura de Lucifer con la de la mascota de
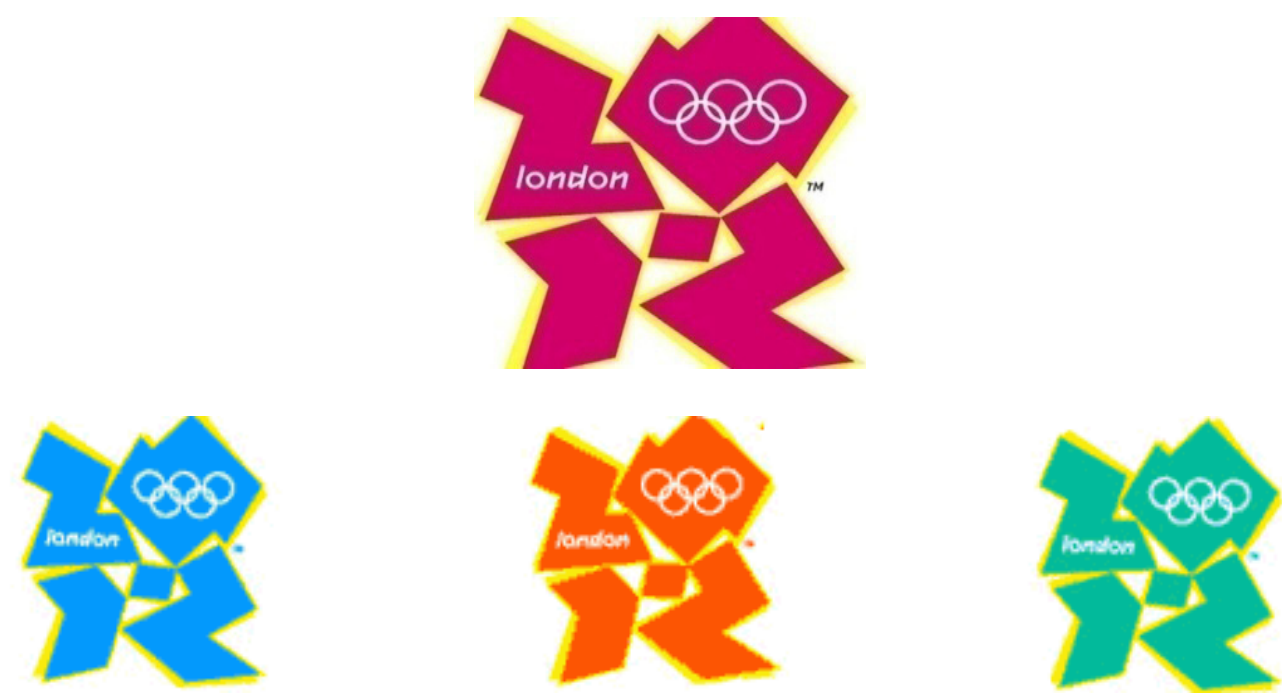

Figura 4. Logo de los Juegos Olímpicos, Londres 2012. Tomado de http://www.london2012.com/games/ (con acceso 22/02/2012).
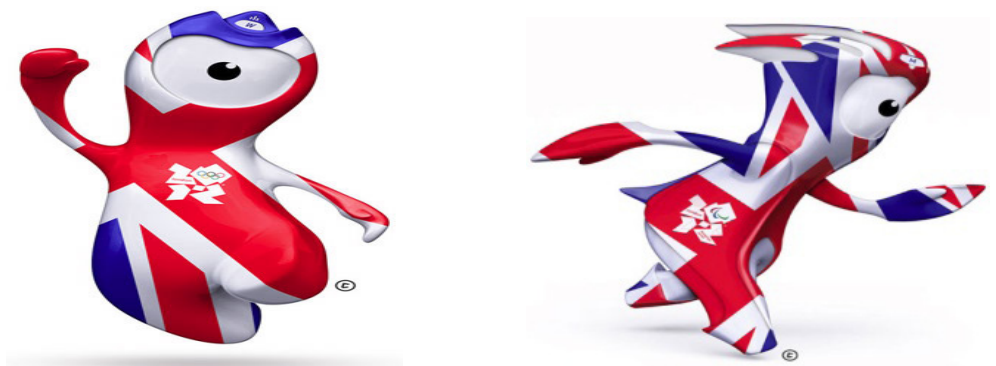

Figura 5. Mascota de los Juegos Olímpicos, Londres 2012. Tomado de: http:/www.london2012.com/games/ (con acceso 22/02/2012). 
los J.J.O.O. de Londres. Destacó sus enormes coincidencias y manifestó que se trataba de “...un mensaje subliminal que incide en las nuevas generaciones y, por tanto, no debe ser aceptado sino que debemos manifestarnos en contra de ella".

Londres celebra los J.J.O.O. modernos por tercera vez; Atenas, los ha celebrado dos veces. En los Juegos Olímpicos de Atenas, de 1896, participaron 241 deportistas, hombres y ninguna mujer, oficialmente, 14 países y nueve deportes, en 43 competencias. La premiación fue: al primero: medalla de plata, ramo de olivos y diploma y, al segundo: medalla de cobre, corona de laurel y diploma. No se sabe por qué al primero no se otorgaba oro.

En Londres participarán más de 100 países, con alrededor de 10.000 deportistas, 26 deportes, 39 disciplinas, 302 competencias en 640 sesiones, del 27 de julio al 12 de agosto de 2012. La premiación consiste en medallas de oro, de plata y de bronce, ramos de flores y reconocimiento especial.

Colombia, esta vez con aceptable financiación, ha venido desarrollando un proceso con base científica, que ha empezado a dar resultado en los diferentes compromisos deportivos: Juegos Nacionales; Bolivarianos; Suramericanos; Centroamericanos y del Caribe; Panamericanos; Olímpicos Juveniles; Juegos Olímpicos de Invierno y Paralímpicos, lo anterior, con la esperanza de participar con éxito en los juegos mundiales, que se realizarán en el la ciudad de Cali, Colombia, del 25 de julio al 4 de Agosto de 2013.

El COC enfrentará el compromiso, este año en Londres, con cerca de 100 atletas, en deportes que están con más opción al pódium, entre otros: atletismo, pesas, boxeo, tiro, arquería, ciclismo, judo, lucha, gimnasia y natación, especialmente, los deportes individuales. Todo el país respalda, acompaña y desea la mejor de las victorias, a nuestros representantes en estos juegos.

La cátedra de estudios olímpicos, con su comité de élite conformado por especialistas en filosofía, en bellas artes, en políticas deportivas, en economía, en sociología y en historia, liderados por el Rector de la U.D.C.A, orienta, profundiza y difunde el olimpismo y, por ello, durante todo el 2012, lo celebraremos, como "Año Olímpico", con diferentes actividades, de forma permanente dentro y fuera de la Universidad, así: Alfabetización Olímpica en las facultades de la Universidad y en los colegios e instituciones educativas del entorno, celebraremos dos foros olímpicos: uno en cada semestre del año; así mismo, tendremos permanente información sobre los J.J.O.O. por medio de videos, de carteleras y de boletines de prensa y celebraremos un símil de la inauguración, en la misma semana de los Juegos, justificando así el "Por qué de una Cátedra Olímpica".

Agradecimientos: A la Universidad de Ciencias Aplicadas y Ambientales U.D.C.A, por fomentar la Cátedra Olímpica. Conflicto de intereses: El autor declara que no existe ningún conflicto de intereses que ponga en riesgo la validez de la información presentada.

\section{BIBLIOGRAFÍA}

1. COMITÉ OLÍMPICO ESPAÑOL COE. AO INTERNACIONAL. s.f. Historia. Disponible desde internet en: www. coe.es (con acceso 21/02/2012).

2. COMITÉ OLÍMPICO INTERNACIONAL COI. 2009. Juegos Olímpicos 2012. Disponible desde Internet en: www.olimpicos.biz/2009/11/comite-olimpico-internacional-coi.html (con acceso 22/02/2012).

3. DIEM, C. 1966. Historia de los deportes. De Cabalat, L.(ed).Registro 1626-66 España. Tomos I y II, España, respectivamente, 479 y 431 p.

4. DURANTEZ, C. 2010. Filosofía del Olimpismo. Conferencia dictada con motivo de la quincuagésima tertulia de la AOC.- Academia de la Lengua. Bogotá, junio de 2010.

5. DURANTEZ, C. 1975. OLIMPIA y los Juegos Olímpicos Antiguos. Tomo I y II. Madrid: Delegación Nacional de Educación Física y Deportes. 298p.

6. GARCÍA, J.A. 2006. De Cero a Gesto. Sección Olimpismo. Ed. Kinesis. 126p.

7. HERNÁNDEZ VÁSQUEZ, M. 2010. El Juego Deportivo en la Prehistoria. Disponible desde Internet en: http://www.museodeljuego.org/_xmedia/menus/0000000054/docu1.pdf (con acceso 105/12/2011).

8. HOMERO. 1998. La Ilíada. Ed. Universales, Bogotá.Canto 23. p.223-233.

9. INTERNATIONAL OLYMPIC ACADEMY I.O.A. 2012. History. Disponible desde Internet en: http://ioa.org.gr/ en/ioa-information/history (con acceso 22/02/2012).

10. JARAMILLO, H.A. 1970. Los deportes. Orígenes, Evolución y Etapa Olímpica. Cronología. Ed. Tercer Mundo. 228p. 
11. KALSIDOU, G. 2011. Conferencia dictada en el $5^{\circ}$ FORO del CEO- U.D.C.A. 27/10/2011.

12. NARANJO, V. 2010a. El primer deportista de la historia. Disponible desde Internet en: http:/teoriaehistoriadeldeportevalennaranjo.blogspot.com/2010/05/ el-primer-deportista-de-la-historia.html (con acceso 05/12/20111/).

13. NARANJO, V. 2010b. Del deporte antiguo - Orígenes del deporte. Disponible desde Internet en: http://teoriaehistoriadeldeportevalennaranjo.blogspot.com/ (con acceso 10/01/12).
14. QUIROGA, S.R. 2000. Educación olímpica: La Academia Olímpica Internacional. Revista digital. 5(20):2. Buenos Aires. Disponible desde Internet en: http:// www.efdeportes.com/ revista digital (con acceso 23/02/2012).

15. SALGADO, M. 2009. Breve reseña histórica. Conferencia ofrecida a estudiantes del programa "Técnicos en entrenamiento deportivo”, U.D.C.A, Marzo 30/2009.

Recibido: Diciembre 16 de 2011

Aceptado: Marzo 1 de 2012 